\title{
Polymers of $N$-Vinylpyrrolidone: Synthesis, Characterization and Uses
}

\author{
F. HAAF, A. SANNER, and F. STRAub \\ Kunststofflaboratorium, BASF Aktiengesellschaft \\ D-6700 Ludwigshafen, West-Germany
}

(Received August 20, 1984)

\begin{abstract}
Polyvinylpyrrolidone (PVP) having molecular weights $\left(M_{w}\right)$ from 2500 to about 1 million is mainly obtained by radical polymerization in solution. The higher molecular weight type products are polymerized in aqueous solution mostly using hydrogen peroxide as initiator. The polymers thus obtained have hydroxyl and carbonyl end groups. More stable end groups can be obtained by polymerization in solvents, which may act as chain transfer agents and which produce low molecular weight type products. Copolymers especially with monomers such as vinyl acetate and with various acrylic compounds may also be produced by solution polymerization. Popcorn polymerization leads to insoluble PVP. Thereby VP is polymerized without initiator in the presence of small amounts of bifunctional monomers. The polymeric flakes thus formed are highly crosslinked, mainly due to entanglements. The molecular weight distribution of soluble PVP is broad due to transfer reactions. An unusual property of PVP is its solubility in water as well as in various organic solvents. The glass transition temperature of high molecular weight polymers $\left(M_{w}=1\right.$ million) is about $175^{\circ} \mathrm{C}$ and falls to values under $100^{\circ} \mathrm{C}$ with decreasing molecular weight $M_{w}=$ 2500). PVP forms complexes with various compounds, especially with $\mathrm{H}$-donors such as phenols and carboxylic acids. The complex formed with cross-linked PVP and polyphenols is used commercially for the clarification of beverages. Another commercial use is the complexation of iodine with linear PVP, which leads to effective disinfectants of very low toxicity. Further important applications of PVP in the pharmaceutical field are their use as binding or film forming agents for tablets, and as solubilizing agents for injections. The swelling ability of cross-linked PVP in water is used in disintegrating agents for tablets. In the cosmetic field VP polymers are used as film formers for hair dressing products. Examples of technical applications are adhesives, textile auxiliaries and dispersing agents.

KEY WORDS Poly- $N$-vinylpyrrolidone / Polymerization / Copolymers / Cross-linked Polymers / Properties / Applications /
\end{abstract}

Polyvinylpyrrolidone, also called Povidone or briefly PVP, is one of the numerous products ${ }^{1,2}$ of the acetylene chemistry founded by Reppe. By reaction of acetylene with formaldehyde, 1,4-butine diol is obtained which is hydrogenated to butane diol. After oxidative cyclization to butyrolactone and its reaction with ammonia, pyrrolidone is formed by the removal of water. Finally the vinyl group is introduced to form $N$-vinylpyrrolidone-2 (1-(2-oxo-pyrrolidinyl)-ethylene). The course of these reactions is shown in Figure 1.

The polymerization of vinylpyrrolidone produces the polymeric material (Figure 2).

In the course of their 40-year history, vinylpyrrolidone polymers have been extensively used, es- pecially in the pharmaceutical, cosmetic and food industry as well as for numerous technical applications. In these various fields PVP has rather different functions. Because there are considerable differences in the requirements, which polymers have to meet for these diverse applications, three types of PVP are offered, namely homopolymers of different molecular weights, copolymers and crosslinked PVP.

\section{POLYMERIZATION OF VINYLPYRROLIDONE}

Vinylpyrrolidone can be polymerized either in bulk, in solution or in suspension. 


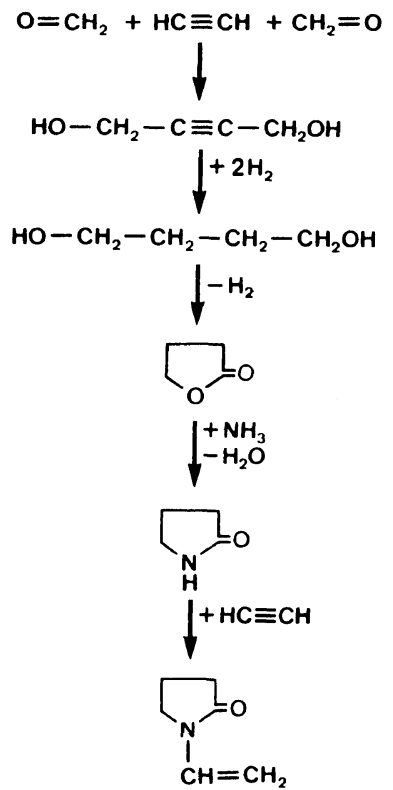

Figure 1. Synthesis of $N$-vinylpyrrolidone from acetylene and formaldehyde.

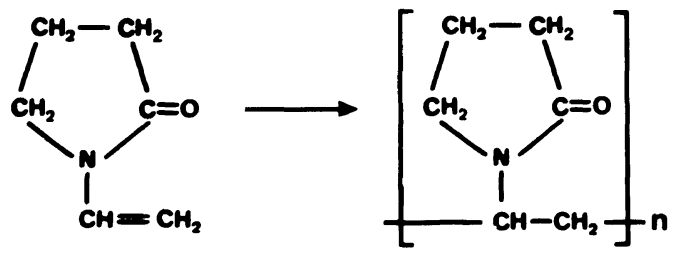

Figure 2. Polymerization of vinylpyrrolidone.

The cationic polymerization with $\mathrm{BF}_{3}$ only leads to oligomers ${ }^{3,4}$ and has no technical importance.

Polymers with degrees of polymerization of 10 100,000 are obtained by radical polymerization. This corresponds to molecular weights of $1,000-10$ million. In industry polymers having molcular weights of 2,500-1 million are mainly produced (Table I).

Vinylpyrrolidone is generally polymerized in aqueous solution using hydrogen peroxide as initiator. ${ }^{5}$ Figure 3 shows a simplified scheme.

Thereby the molecular weight is regulated by the concentration of hydrogen peroxide, i.e., the higher the amount of hydrogen peroxide the lower the molecular weight of the polyvinylpyrrolidone produced. In aqueous solution hydroxy radicals are generated from hydrogen peroxide, thus forming the end groups of the polymer. However, in most
Table I. $K$-Value and molecular weights of PVP polymerized in solution

\begin{tabular}{|c|c|c|c|}
\hline \multirow{2}{*}{$K$-Value } & {$[\eta]$} & \multirow{2}{*}{$M_{w}$} & \multirow{2}{*}{$M_{n}$} \\
\hline & $\mathrm{dl} \mathrm{g}^{-1}$ & & \\
\hline 12 & 0.05 & $2,500^{\mathrm{c}}$ & 1,300 \\
\hline 17 & 0.09 & $10,000^{\mathrm{a}}$ & $2,500^{\mathrm{b}}$ \\
\hline 25 & 0.16 & $25,000^{\mathrm{a}}$ & $6,000^{\mathrm{b}}$ \\
\hline 30 & 0.22 & $40,000^{\mathrm{a}}$ & $10,000^{\mathrm{b}}$ \\
\hline 90 & 1.6 & 1.1 Milion $^{\mathrm{a}}$ & $150,000^{\mathrm{c}}$ \\
\hline
\end{tabular}

cases an aldehyde functional group is found as the second end group. This can be explained by the fact that the second hydroxyl end group, which is formed during chain termination, continues to react by splitting off pyrrolidone. Consequently polyvinylpyrrolidone produced in aqueous solution contains small amounts of pyrrolidone. No evidence can be found for other chain termination reactions such as disproportionation.

The polymerization of vinylpyrrolidone in organic solvents such as alcohols, toluene, etc. proceeds in a more complicated way (Figure 4).

Using organic peroxides such as di-tertiary-butylperoxide or dicumyl peroxide, alkoxy radicals are formed, which produce solvent radicals by $\mathrm{H}$ abstraction. In this case it is this solvent radical, not the alkoxy radical of the initiator, which initiates the polymerization. While the chain propagation proceeds as expected, it was proved that the chain termination takes place by $\mathrm{H}$ abstraction from the solvent - and hardly by recombination or disproportionation. An alkyl end group and a solvent radical are formed; the solvent radical again initiates polymerization. The proof for this polymerization mechanism is obtained by H NMR spectroscopy (Figure 5).

In the case of carefully purified polymers produced in toluene using di-tertiary-butyl peroxide, the presence of aromatic groups of the toluene can clearly be seen in the NMR-spectrum, though the polymer product no longer contained any residual solvent (gas chromatographic measurements). Similarly the H NMR spectrum as well as the ${ }^{13} \mathrm{C}$ NMR spectrum of polymers, which are produced in isopropanol solution with dicumyl peroxide as 
Polymers of $N$-Vinylpyrrolidone: Synthesis, Characterization, and Uses Initiation:

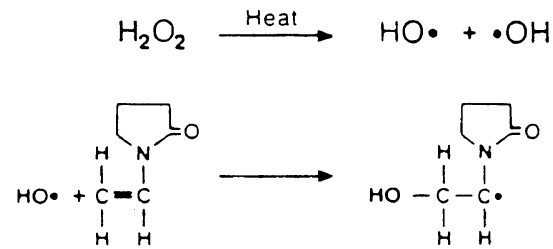

\section{Propagation}

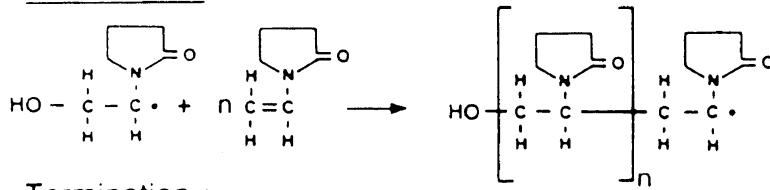

Termination :
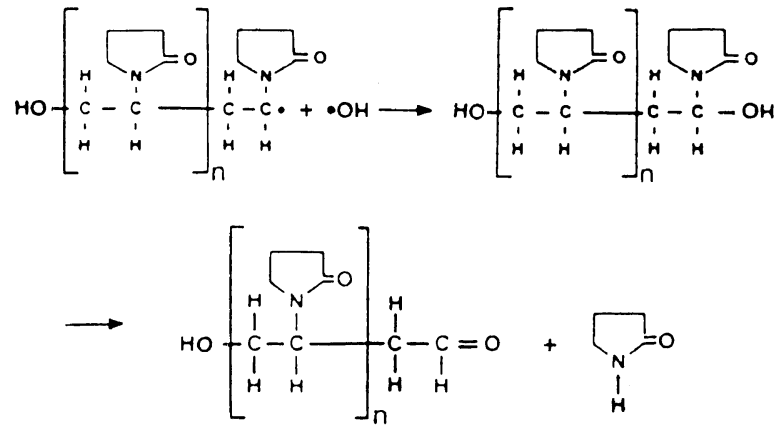

Figure 3. Polymerization mechanism of VP in aqueous solution.

Initiation:

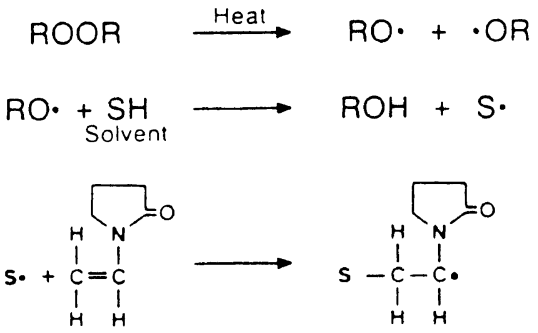

Propagation :

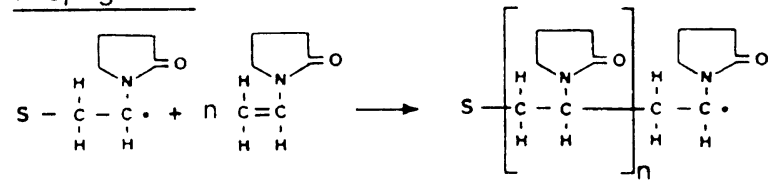

Termination by Chain Transfer:

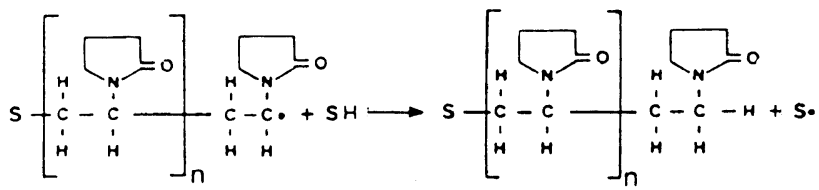

Figure 4. Polymerization mechanism of VP in organic solution. 


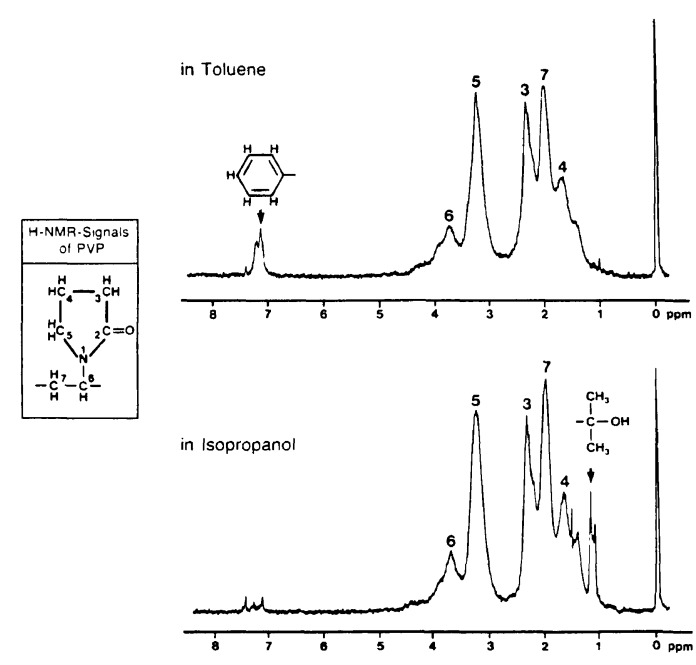

Figure 5. NMR-spectra of PVP polymerized in organic solvents.

initiator, show the fragments of isopropanol. Polyvinylpyrrolidone produced in organic solution in the presence of peroxides contains an end group of the solvent radical and a hydrogen atom from termination due to chain transfer. Since there is no splitting off of any pyrrolidone at the polymer end, these polymer products are purer and-due to the lack of aldehyde end groups-more stable towards oxidizing agents than those products, which are polymerized in water with hydrogen peroxide as the initiator.

In the case of the polymerization in organic solution, low molecular weights are obtained due to the transfer reactions of the solvent. In aqueous solution using hydrogen peroxide, medium degrees of polymerization are obtained. Higher molecular weight products may also be produced in aqueous solution, however, in the presence of organic initiators.

\section{PROPERTIES OF POLY- VINYLPYRROLIDONE}

As it is typical for all radical polymerizations, polymerization of vinylpyrrolidone gives a SchulzFlory molecular weight distribution (Figure 6).

In the case of high molecular weight products, the distribution is broader than in the case of lower molecular weight polymers. This can be explained by a more intense branching occuring during the

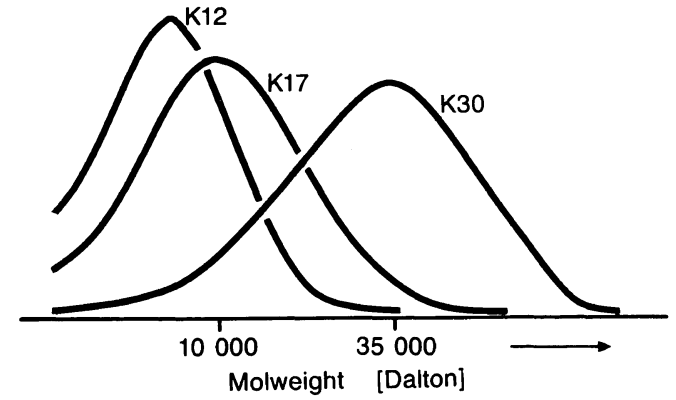

Figure 6. Gel permeation chromatography of PVP. Conditions: aqueous solution with $0.08 \mathrm{~m}$. Tri(hydroxymethyl)aminomethan $/ \mathrm{HCl}, \mathrm{pH}$ 4.65. Flow rate $1 \mathrm{ml} / \mathrm{min}, 23^{\circ} \mathrm{C}$

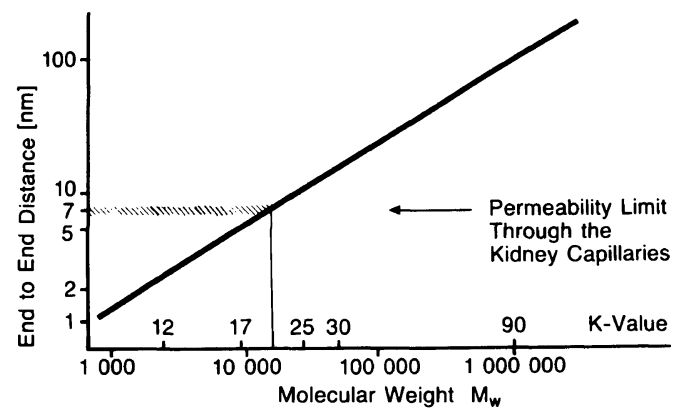

Figure 7. End to end distance of the coiled chains $v s$. $K$-value and molecular weight. Solvent: $0.9 \% \mathrm{NaCl}$ in water.

formation of the high molecular weight products due to grafting of the polymer chain.

Polyvinylpyrrolidone in solution probably exists as a random coil; suggestions in the literature ${ }^{6}$ concerning a possible helix structure have not yet been proved. Depending on the molecular weight, the coil dimensions (average end to end distance) are between $1-100 \mathrm{~nm}(10-1,000 \AA)$ in an aqueous solution of sodium chloride (Figure 7).

The size of the coil is important for applications in the medical field. The size is related to the ability of the human body to excrete the polymer. The diameter of the capillaries of the human kidney ${ }^{7}$ is about $7 \mathrm{~nm}$, i.e., polymers having molecular weights below 30,000 , corresponding to a diameter $<7 \mathrm{~nm}$, are able to pass through the kindey and are excreted. Since all polymers produced by radical polymerization have a molecular weight distribution, only polymers of polyvinylpyrrolidone, which do not contain any significant portion with molecular weights above 30,000 , should be used for 
Table II. Solubility of PVP in various solvents

\begin{tabular}{ll}
\hline $\begin{array}{l}\text { Soluble in: } \\
\text { Water }\end{array}$ & $\begin{array}{l}\text { Di(ethylene glycol) } \\
\text { Pethanol }\end{array}$ \\
Ethanol & Propylenylene glycol 400 \\
Propanol & 1,4-Butanediol \\
Butanol & Glycerol \\
Cyclohexanol & $N$-Vinylpyrrolidone \\
Chloroform & Triethanolamine \\
Dichloromethane & Formic acid \\
1,2-Dichloroethane & Acetic acid \\
$N$-Methylpyrrolidone & Propionic acid \\
Ethylenediamine & \\
Insoluble in: & \\
Ethyl acetate & Carbon tetrachloride \\
Acetone & Light petroleum \\
Dioxane & Toluene \\
Diethyl ether & Xylene \\
Pentane & Mineral oil \\
Cyclohexane & \\
\hline
\end{tabular}

injections with human beings in order to secure good elimination: These are polymers having a molecular weight average $\left(M_{w}\right)$ of about 2,500 .

A special and unusual property of polyvinylpyrrolidone is its solubility in water as well as in various organic solvents. The reason for this is, that PVP has hydrophilic as well as hydrophobic functional groups and therefore interactions with various solvents are possible.

Aqueous solutions show the unusual behaviour that the viscosity in contrast to most other aqueous polymer solutions is not affected by electrolytes. ${ }^{8}$

Polymers with molecular weights $\left(M_{w}\right)$ of more than 1 million are generally used as thickening agents. Concerning the solubility of the polyvinylpyrrolidone a peculiarity has to be pointed out. Commercially used polyvinylpyrrolidone is soluble - as it can be seen from Table II-in most polar solvents and insoluble in the less polar ones. However, if polyvinylpyrrolidone is produced completely free of water - this is difficult because of its high hygroscopicity - it can also be dissolved in solvents such as dioxane, acetone and toluene. ${ }^{9}$

Polyvinylpyrrolidone cannot be processed in the melt, because of its low decomposition temperature and the extremely poor flow properties of the melt. Films coated from solution are very brittle, clear and glossy.

The glass transition temperature increases with molecular weight and reaches a plateau at about

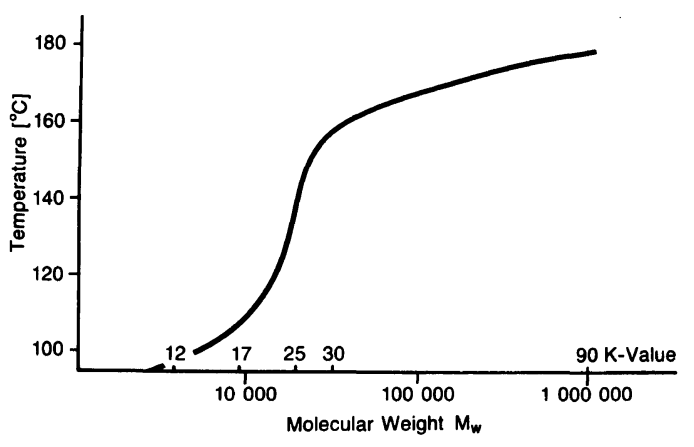

Figure 8. Glass transition temperature vs. molecular weight.

$175^{\circ} \mathrm{C}^{10}$ which corresponds to a molecular weight of 100,000

At low molecular weights the glass transition temperature falls to values below $100^{\circ} \mathrm{C}$ (Figure 8). The addition of small amounts of water also leads to lower glass transition temperatures.

\section{VINYLPYRROLIDONE COPOLYMERS}

The preparation of vinylpyrrolidone copolymers is carried out by copolymerization in solution, whereby in most cases the comonomers are slowly added to the vinylpyrrolidone monomer to obtain a more homogeneous composition of copolymers, which otherwise, because of the great disparity of the copolymerization parameters, ${ }^{11}$ would not be formed. Copolymers can be formed with numerous monomers by radical polymerization. However, there are only few copolymers, which are produced technically in large amounts.

The copolymers are produced to alter or to improve certain properties of the polyvinylpyrrolidone. For example, the hygroscopicity of PVP, which is too high for many applications, is reduced by copolymerizing vinylpyrrolidone with various amounts of vinyl acetate or vinyl propionate (Figure 9). Some of these copolymers are no longer water-soluble, but the water adsorption in the dry state can be reduced by more than $50 \%$.

Copolymers with cationic functional groups are advantageous for certain applications. For example, they generate better adhesion to the hair leading to a better curl retention (Figure 10).

The lactam group in polyvinylpyrrolidone has no measurable cationic activity. Cationic polymers may be produced with monomers, which carry 


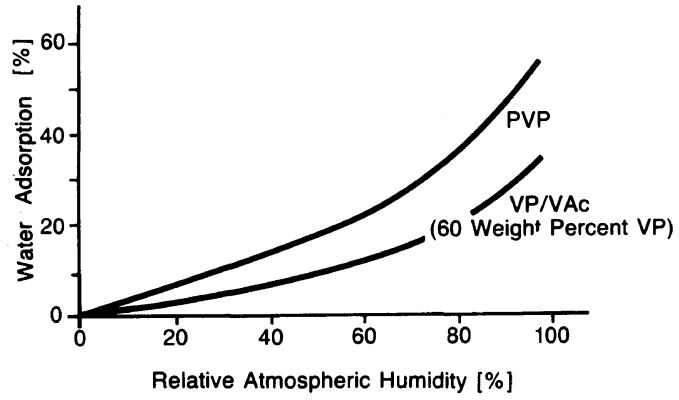

Figure 9. Hygroscopicity of PVP and a VP-copolymer at $23^{\circ} \mathrm{C}$.

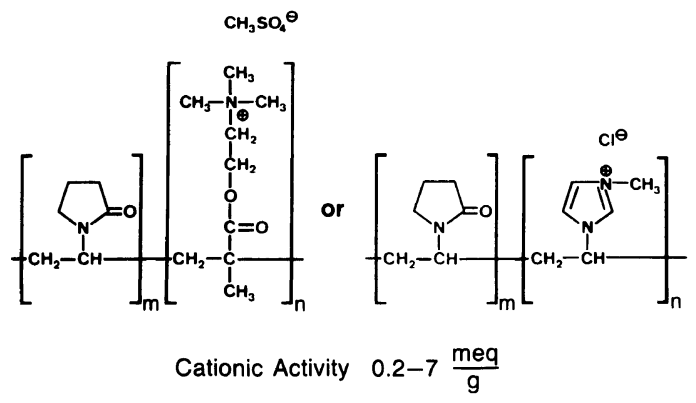

Figure 10. Copolymers of VP and cationic monomers.

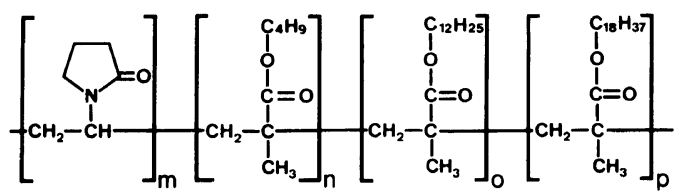

Figure 11. Copolymers of VP with butyl methacrylate, lauryl methacrylate and stearyl methacrylate.

nitrogen groups of high basicity or which can be converted to cationic monomers by quaternization reactions. Examples for monomers of this kind are aminoalkyl methacrylates and vinylimidazole. The quaternization of the nitrogen group in these monomers with dimethyl sulphate or alkyl halides such as methyl chloride can be carried out before or after the polymerization process.

For the production of copolymers having anionic functional groups, monomers such as acrylic acid, methacrylic acid as well as maleic anhydride are used.

However, it should be taken into consideration that during polymerization in the presence of water, traces of acid cause vinylpyrrolidone to decompose into acetaldehyde and pyrrolidone. ${ }^{12}$

Copolymers can be easily produced with various methacrylates, if an appropriate organic solvent is used.

Such copolymers are even soluble in oil and are used as dispersing agents (Figure 11).

\section{CROSS-LINKED POLY- VINYLPYRROLIDONE}

There are various methods reported in the literature concerning the production of cross-linked vinylpyrrolidone polymers. The subsequent crosslinking of linear PVP is achieved, for example, by $\gamma$ radiation $^{13}$ or by treatment of the polymer with persulphate ${ }^{14}$ or with hydrazine and hydrogen peroxide $^{15}$ or with $\alpha, \omega$-diolefines in the presence of peroxides. ${ }^{16}$ The products obtained are only slightly cross-linked and form soft gels in solvents dissolving linear PVP. More densely cross-linked products are obtained by copolymerization of vinylpyrrolidone with cross-linking agents such as multiple unsaturated compounds. ${ }^{17}$

The popcorn polymerization (proliferous polymerization) leads to highly cross-linked PVP. This completely insoluble cross-linked PVP, called crospovidone, is of industrial importance. Its main uses are as an agent for clarifying beverages, as a tablet disintegrant and as an agent against diarrhoea.

A radical mechanism is assumed for the popcorn polymerization. However, no radical initiator is required for the popcorn formation. The main source of radicals comes from the rupture of polymer chains already formed. ${ }^{18}$ The radical initiator is also omitted in the industrial production of the crospovidones.

The patent literature describes two production

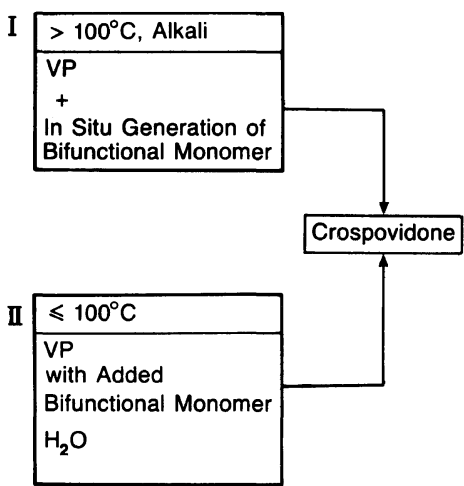

Figure 12. Proliferous (popcorn) polymerization. 


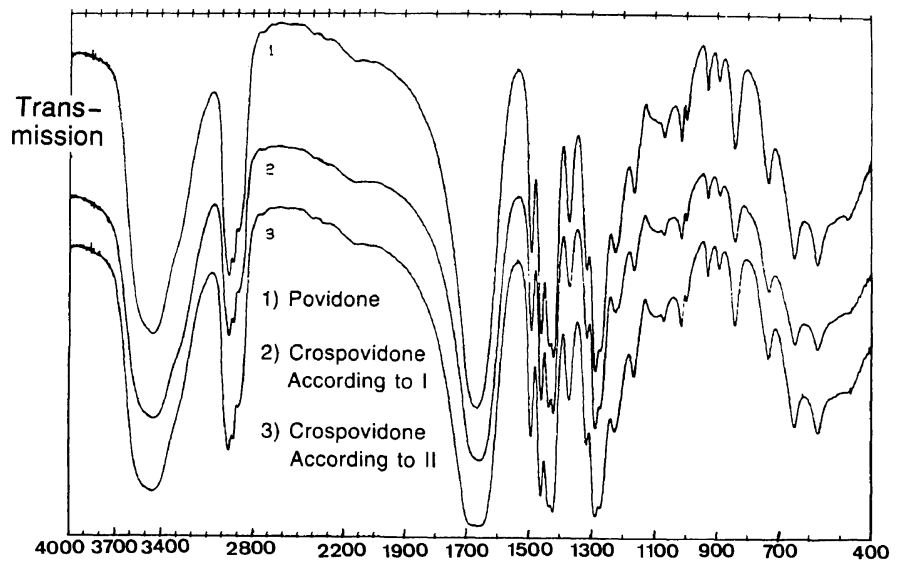

Figure 13. IR-spectrum of PVP and crospovidone.

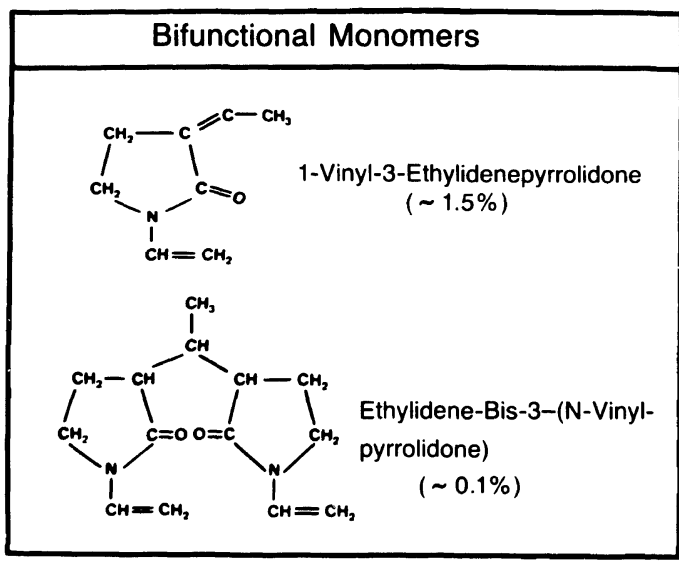

Figure 14. Bifunctional monomers formed in popcornpolymerization according to U.S. Patent 2938017.

processes, which are shown in Figure 12.

In process I vinylpyrrolidone is heated in the presence of an alkali metal hydroxide to above $100^{\circ} \mathrm{C} .{ }^{19}$ In the other process II an aqueous solution of vinylpyrrolidone is warmed in the presence of a small amount of a bifunctional monomer $\left(<2 \mathrm{~mol}^{\circ} \%\right)$ to about $100^{\circ} \mathrm{C}{ }^{20}$ The resulting polymers do not differ in their IR spectra. As can be seen from Figure 13, both popcorn polymers have the same IR spectrum as linear PVP.

The bifunctional monomers formed in situ in the course of process I are 1-vinyl-3-ethylidene pyrrolidone and ethylidene-bis-3( $N$-vinyl-pyrrolidone) (Figure 14). They were found to be present in amounts of 1.5 and $0.1 \%$, respectively, using gas

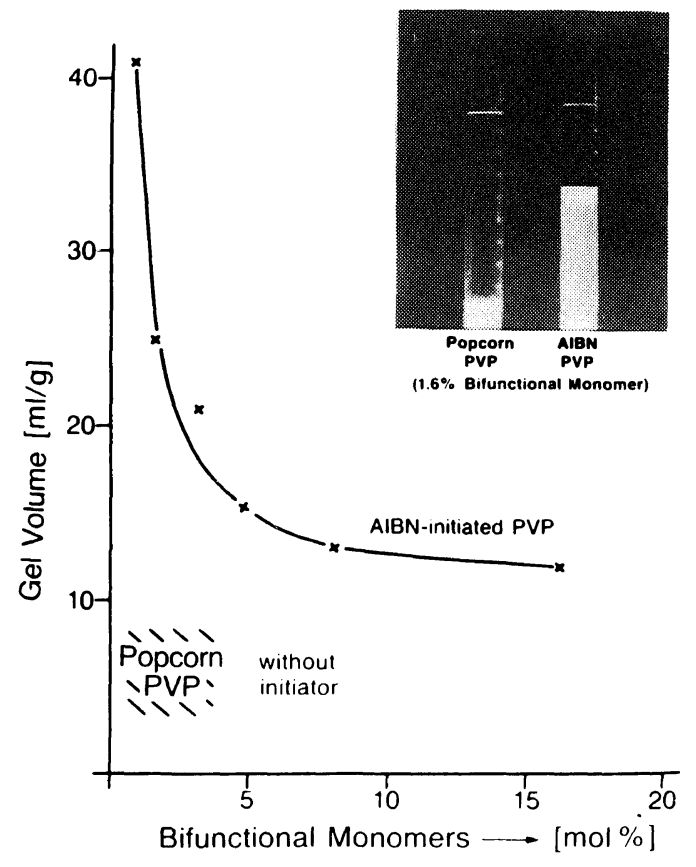

Figure 15. Swelling of AIBN-initiated PVP and popcorn-PVP in water.

chromatography, mass spectroscopy as well as thinlayer chromatography on reaction mixtures, which had been stopped by cooling.

After the polymerization is complete, the bifunctional compounds cannot be traced in the finished product, regardless of the polymerization process which has been used.

Popcorn PVP, independant of its preparation by 
Table III. $T_{\mathrm{g}}$ and gel volume of linear and crosslinked PVP from DSC

\begin{tabular}{|c|c|c|}
\hline \multirow{2}{*}{ Sample } & $T_{\mathrm{g}}$ & Gel volume \\
\hline & ${ }^{\circ} \mathrm{C}$ & $\mathrm{mlg}^{-1}$ \\
\hline Povidone & 175 & $\infty$ \\
\hline Crospovidone according to I & 190 & 5 \\
\hline $\begin{array}{l}\text { Crospovidone according to II } \\
\text { Copolymer of VP with }\end{array}$ & 195 & 5 \\
\hline $\begin{array}{l}1.6 \mathrm{~mol} \% \text { bifunctional monomer } \\
\text { (initiator: AIBN) }\end{array}$ & 195 & 42 \\
\hline Copolymer of VP with & & \\
\hline $\begin{array}{l}16 \mathrm{~mol} \% \text { bifunctional monomer } \\
\text { (initiator: AIBN) }\end{array}$ & 270 & 12 \\
\hline
\end{tabular}

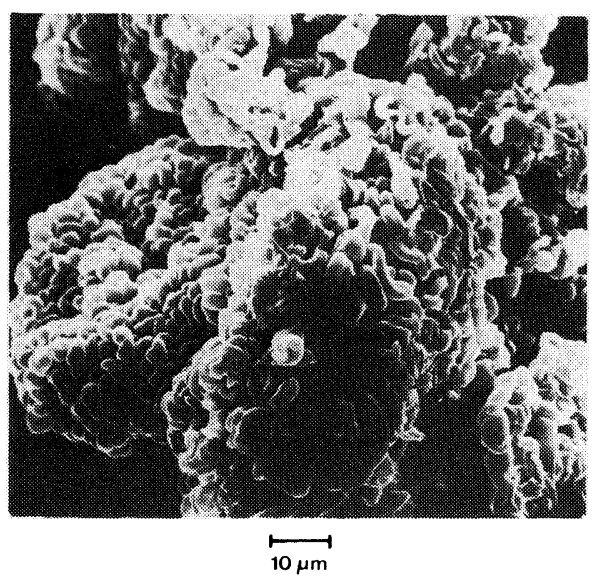

Figure 16. Surface of crospovidone. Total surface by $\mathrm{Hg}$-porosimetry, $62 \mathrm{~m}^{2} \mathrm{~g}^{-1}$.

either process I or II, is considerably more crosslinked than vinylpyrrolidone polymerized in the normal way with free radical initiators in solution using even larger amounts of bifunctional monomers as cross-linking agents. PVP with, for example, $1.6 \%$ bifunctional monomer polymerized with initiator AIBN is far less cross-linked than popcorn PVP with $1.6 \%$ bifunctional monomer without any initiator (Figure 15).

Since the IR spectra show no difference between cross-linked PVP and soluble PVP, the number of chemical cross-links must therefore be small and we have to assume that popcorn polymers are mainly physically cross-linked. This assumption is supported by DSC studies (differential scanning calorimetry), which were carried out to investigate the
Table IV. Applications of VP-polymers

Pharmaceuticals: Binder, coating and disintegrant for tablets stabilizer, solubilizer for suspensions and solutions disinfectant (PVP-I) adsorbent

Cosmetics: $\quad$ Film formers for hair sprays, setting lotions and conditioning shampoos

Food: $\quad$ Stabilization of beverages

Adhesives: Adhesive sticks, water remoistenable adhesives

Polymers: $\quad$ Suspending agent in two phase polymerization systems

Textiles: Dye-affinitive stripping and levelling agent

Table V. Constants of the interaction of drugs and model compounds with povidone and crospovidone in $0.1 \mathrm{~N} \mathrm{HCl}$ at $25^{\circ} \mathrm{C}$

\begin{tabular}{|c|c|c|}
\hline \multirow{2}{*}{ Compound } & \multicolumn{2}{|c|}{$\begin{array}{l}\text { Interaction constant }^{\mathrm{a}} \\
K / \mathrm{l} \mathrm{mol}^{-1}\end{array}$} \\
\hline & Povidone & Crospovidone \\
\hline \multicolumn{3}{|l|}{ Active drugs: } \\
\hline Acetylosalicyclic acid & 0.7 & 2.1 \\
\hline Chloramphénicol & 0.4 & $\sim 0$ \\
\hline Chlorpromazine & 1.0 & 1.2 \\
\hline Methylparaben & 1.8 & 4.2 \\
\hline Sulfathiazole & 0.4 & 1.0 \\
\hline Trimethoprime & 0.2 & $\sim 0$ \\
\hline \multicolumn{3}{|l|}{ Model compounds: } \\
\hline Phenol & 0.8 & 2.3 \\
\hline Benzoic acid & 0.9 & 2.6 \\
\hline 3-Hydroxybenzoic acid & 2.8 & 20.5 \\
\hline 3,5-Dihydroxybenzoic acid & & 125.6 \\
\hline Gallic acid & & $>1,000.0$ \\
\hline
\end{tabular}

${ }^{\text {a }} K=[\mathrm{FA}] /[\mathrm{F}][\mathrm{A}] . \quad \mathrm{FA}=$ occupied site; $\mathrm{F}=$ free binding site; $\mathrm{A}=$ free compound.

glass transition temperatures.

The glass transition temperature of the crospovidones formed by popcorn polymerization shown in Table III is only $15-20^{\circ} \mathrm{C}$ higher than that of linear povidone. In contrast to this, the PVP crosslinked chemically with $16 \mathrm{~mol} \%$ bifunctional monomer to give a similar degree of swelling as crospovidone, shows a $T_{\mathrm{g}}$-value of $270^{\circ} \mathrm{C}$ which is $95^{\circ} \mathrm{C}$ above the $T_{\mathrm{g}}$ of the soluble povidone. Another copolymer sample with only $1.6 \mathrm{~mol} \%$ bifunctional monomer gives the same $T_{\mathrm{g}}$ as crospovidone, but 
has a much larger degree of swelling due to the lack of physical cross-links.

Investigations of the supermolecular structure of PVP by X-ray studies did not give any evidence of crystallinity. Since no crystalline domains were found in the popcorn polymer, it has to be concluded that the high cross-link density is due to the entanglements of the polymer chains. This is in agreement with the mechanism for the popcorn polymerization suggested by Breitenbach. ${ }^{18}$ The entanglements occur when the polymer chains rupture due to the swelling caused by the intruding monomer, thus forming radicals, which permit the growth of new chains between those already present.

In addition to the degree of cross-linking, which is characterized by the swelling behaviour, the surface of the polymer particles is of great importance, especially for applications as an adsorbent.

As stereoscan photographs show (Figure 16), popcorn PVP presents itself as voluminous particles. The total suface area determined by mercury porosimetry is near $60 \mathrm{~m}^{2} \mathrm{~g}^{-1}$.

\section{APPLICATIONS}

A survey of the most important applications of vinylpyrrolidone polymers is represented in Table IV.

For uses in pharmaceuticals and foods the interaction of PVP with low molecular weight compounds is important.

Due to its chemical structure, PVP forms complexes with numerous low molecular weight compounds as well as with many polymers. The formation of complexes is due to hydrogen bonding. The ability to form complexes is desirable in many cases, since insoluble substances can thus be solubilized. On the other hand for applications in the pharmaceutical field, too strong complexes are detrimental to the bioavailability of the active substance.

The degree of interaction of a variety of drugs and model compounds with soluble and insoluble cross-linked polyvinylpyrrolidones was investigated by Horn and Ditter. ${ }^{21}$ Equilibrium dialysis and a novel chromatographic technique were used in these investigations. Some of the interaction constants found are represented in Table V.

In the case of almost all the tested drugs, the
Solid State

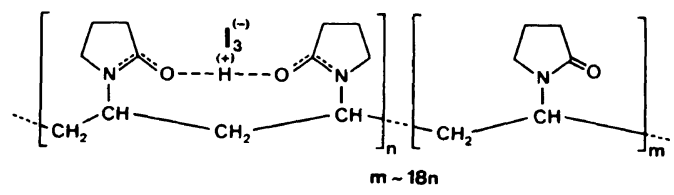

Aqueous Solution (10\% in Water)

$\begin{array}{lr}\text { Available lodine: } & 10,000 \mathrm{ppm} \\ \text { Free lodine: } & 1-2 \mathrm{ppm}\end{array}$

Figure 17. Povidone-iodine.

values for the interaction constants at $\mathrm{pH} 1$ were below the allowed limit of $10 \mathrm{l} \mathrm{mol}^{-1}$. Taking into consideration the common conditions for the oral administration of pharmaceutical preparations, the concentration of PVP is about $0.5 \mathrm{~g}^{-1}$ and the concentration of the active drug is of $1 \times 10^{-4}$ to $2 \times 10^{-3} \mathrm{moll}^{-1}$. From this can be calculated that for interaction constants below $101 \mathrm{~mol}^{-1}$, the bound amount of the drug can hardly exceed $3 \%$. Considering further the fact that the extent of interaction is decreasing with increasing $\mathrm{pH}$ and in view of its reversible character, the presence of these additives is not expected to interfere with the gastrointestinal absorption of the drug.

When looking at the model compounds it is striking to find the extremely high interaction constant of gallic acid with PVP. This effect can be utilised for clearing fruit juices and beer containing polyphenols of similar structure as gallic acids. These polyphenols cause the turbidity of these beverages and are removed by adsorption with the cross-linked polyvinylpyrrolidone.

In the case of PVP-iodine, the ability to form a complex is particulary significant. Various formulations of this complex have been used for years as multivalent, broad-spectrum, local antiseptics having bactericidal, fungicidal and virucidal properties. Based on IR and X-ray studies made with low molecular model compounds in the solid state, the structure as represented in Figure 17 is proposed.

Due to complexation the content of free iodine is extremely low in aqueous solution. ${ }^{22,23}$ In a $10 \%$ solution containing $10,000 \mathrm{ppm}$ of total iodine, only $1-2 \mathrm{ppm}$ are free; the rest exists in a complexed state. Because of this low concentration of free iodine, PVP-iodine solutions are non irritating and mild antiseptics in contrast to the aqueous iodine/ 
potassium iodide solutions, called Lugol solution, and in contrast to the alcoholic solutions, called iodine tincture, both used in former times.

Furthermore, PVP is important for adhesive applications, where it is especially used for adhesive sticks and for remoistenable adehesives. High molecular weight vinylpyrrolidone polymers are also used as protective colloids and particle size regulators for suspension polymerization of styrene, vinyl acetate and vinyl chloride. PVP is used in textile dyeing as a dye affinity stripping and levelling agent.

PVP has found many new applications in recent years due to its unusual properties. By using new polymerization techniques and by copolymerization, the polymer properties can be further modified and improved, so that completely new fields of application are opened up. In most cases PVP is usually present as an essential auxiliary and not as the active substance itself. The continuing interest in PVP is shown by $c a$. 20 publications and $c a .25$ patents per year on this subject, which demonstrates the still growing potential of the polyvinylpyrrolidones.

\section{REFERENCES}

1. BASF, Deutsches Reichspatent 757 355, 1944.

2. W. Reppe, "Polyvinylpyrrolidon," Verlag Chemie, Weinheim, 1954.

3. N. Tsubokawa, N. Takeda, and A. Kanamaru, $J$. Polym. Sci., Polym. Lett. Ed., 18, 625 (1980).

4. M. Biswas and P. Mishra, Polymer, 16, 621 (1975).
5. W. Kern and H. Cherdron, in "Houben Weyl, Methoden der Organische Chemie," Vol. 14, 4th ed., Georg Thieme Verlag, Stuttgart, 1961, p 1106.

6. A. E. Tonelli, Polymer, 23, 676 (1982).

7. J. Orloff, "Handbook of Physiology," Section 8: Renal Physiology, American Physiology Society, Washington D.C., 1973.

8. P. Davison and E. Mentzer, SPE, 9300 (1980).

9. R. L. Davidson and M. Sittig, "Water Soluble Resins," 2nd ed., Reinhold Book Corp., New York, 1968, S. 137 (Table 7.3).

10. Y. Y. Tau and G. Challa, Polymer, 17, 739 (1976).

11. R. Z. Greenley, J. Macromol. Sci., Chem., A14(4), 445 (1980).

12. J. Ferguson and V. S. Ragan, Eur. Polym. J., 15, 627 (1979).

13. A. Henglein, J. Phys. Chem., 63, 1852 (1959).

14. C. C. Anderson et al., J. Appl. Polym. Sci., 23, 2453 (1979).

15. GAF, U.S. Patent 2658045 , November 3, 1953.

16. GAF, U.S. Patent 3350 366, October 31, 1967.

17. DOW, U.S. Patent 3669 103, June 13, 1972.

18. J. W. Breitenbach, "Encyclopedia of Polymer Science and Technology," Vol. 11, 1969, p 587-597.

19. GAF, U.S. Patent 2938017, May 24, 1960; GAF, U.S. Patent 3277066 , October 4, 1966; GAF, U.S. Patent 3306866 , February 28, 1967.

20. BASF, Ger. Patent 2255263, June 5, 1975.

21. D. Horn and W. Ditter, a) J. Pharm. Sci., 71, 1021 (1982); b) "Proceedings of the International Symposium on Povidone," University of Kentucky, April 17-20, 1983, Lexington, U.S.A., p 80-100.

22. D. Horn and W. Ditter, a) See ref 21 b, pp120-140; b) "PVP-Iod in der operativen Medizin," Herausgegeben von G. Hierholzer, und G. Görtz, Springer Verlag, Berlin-Heidelberg, 1984.

23. W. Gottardi, Hyg. Med., 8, 203 (1983). 